\title{
A STUDY OF MICROALBUMINURIA IN ESSENTIAL HYPERTENSION AND ITS CORRELATION WITH THE TARGET ORGAN DAMAGE
}

\author{
Ramakrishna $G^{1}$, Venkata Venu Gopala Raju $S^{2}$, Chaitanya $G^{3}$, Indhira $D^{4}$
}

${ }^{1}$ Assistant Professor, Department of General Medicine, Katuri Medical College.

2Professor, Department of Physiology, Katuri Medical College.

${ }^{3}$ Associate Professor, Department of Community Medicine, Katuri Medical College.

${ }^{4}$ Post Graduate Student, Department of General Medicine, Katuri Medical College.

\section{ABSTRACT}

Hypertension is one of the most common disease afflicting humans throughout the world. Target organ damage resulting from hypertension includes those affecting the brain, heart, kidneys and the eyes. Focal neurological deficits, dyspnoea, chest pain, headache, loss of vision are considered as the commonest symptoms with which patients having hypertension related acute target organ damage present.

\section{OBJECTIVES}

To assess the prevalence of micro-albuminuria among the non-diabetic hypertensive patients and to assess the relationship between micro-albuminuria and target organ damage.

\section{MATERIALS AND METHODS}

A cross-sectional study was conducted in 100 hypertensive patients microalbuminuria was measured in these patients by micral dipstick method. Chi-square test was used to study the relationship between microalbuminuria and other variables. P value was calculated for all the variables.

\section{RESULTS}

The prevalence of microalbuminuria was $23 \%$ among the non-diabetic hypertensive patients. A positive correlation between microalbuminuria and target organ damage was found in these patients. The odds ratio for microalbuminuric patients having retinopathy was $8.3 \%$ (95\% confidence interval 2.4-37.5). Prevalence of microalbuminuria was higher among patients with Cerebrovascular Accidents $(\mathrm{P}<0.001)$ with the odds ratio of $15.3(95 \%$ confidence interval $4.9-47.5)$ and it was observed that there was significant correlation between the prevalence of microalbuminuria and the presence of LVH $(\mathrm{P}<0.001)$ with the odds ratio of 10.4 (95\% confidence interval 3.52-30.8) in hypertensive patients.

\section{CONCLUSION}

Microalbuminuria had a statistically significant correlation with the target organ damage. Extensive screening for microalbuminuria is required in hypertensive subjects to assess the cardiovascular risk.

\section{KEYWORDS}

Hypertensive Patients, Microalbuminuria, Target Organ Damage.

HOW TO CITE THIS ARTICLE: Ramakrishna G, Venkata Venu Gopala Raju S, Chaitanya G, Indhira D. "A Study of Microalbuminuria in Essential Hypertension and its Correlation with the Target Organ Damage." Journal of Evolution of Medical and Dental Sciences 2015; Vol. 4, Issue 99, December 10; Page: 16404-16406, D0I: 10.14260/jemds/2015/2429

\section{INTRODUCTION \\ Hypertension is one of the most common disease afflicting humans throughout the world.(1,2) Because of the associated morbidity and mortality and the cost to society, hypertension is an important public health challenge. Over the past several decades, extensive research, widespread patient education, and a concerted effort on the part of health care professionals have led to decreased mortality and morbidity rates from the multiple organ damage arising from years of untreated hypertension. $(1,3,4)$ \\ Wide variability in the incidence of microalbuminuria in various studies may be related to the severity and control of hypertension, selection criteria, racial differences, etc. The relationship between blood pressure and risk of cardio- vascular disease events is continuous, consistent and independent of other risk factors.}

Financial or Other, Competing Interest: None.

Submission 18-11-2015, Peer Review 19-11-2015,

Acceptance 02-12-2015, Published 08-12-2015.

Corresponding Author:

Dr. Venkata Venu Gopala Raju S,

Professor of Physiology,

Katuri Medical College \& Hospital,

Guntur-522019, Andhra Pradesh, India.

E-mail: drvenugopalkmc@gmail.com

DOI:10.14260/jemds/2015/2429
Target organ damage resulting from hypertension includes those affecting the brain, heart, kidneys and the eyes.(5) A number of cardiovascular, pulmonary and neurological symptoms are found to be associated with hypertensive patients having target organ involvement. Focal neurological deficits, dyspnoea, chest pain, headache, loss of vision are considered as the commonest symptoms with which patients having hypertension related acute target organ damage present.(6) With this background, our study was aimed to assess the prevalence of microalbuminuria among the nondiabetic hypertensive patients and to assess the relationship between microalbuminuria and target organ damage.

\section{MATERIALS AND METHODS}

A cross-sectional study was conducted in patients attending the Department of General Medicine Department, Katuri Medical College and Hospital, Guntur. Patients diagnosed with hypertension were included in the study after fulfilling inclusion and exclusion criteria. The study was conducted for a period of 3 months. A predetermined proforma was used to record the details of history, physical examination and investigations. Microalbuminuria was assessed by urine Micral Strip test. Chi-square test was used to study the relationship between microalbuminuria and other variables.

$P$ value was calculated for all the variables. For those variables with significant $P$ value, odds ratio was calculated. 


\section{Inclusion Criteria}

1. Patients who were under the treatment for hypertension and newly diagnosed hypertensives with systolic BP $>140$ and diastolic $\mathrm{BP}>90 \mathrm{mmHg}$.

2. Age group included was 30 to 80 years.

\section{Exclusion Criteria}

1. Patients with overt proteinuria, congestive cardiac failure, renal failure, urinary tract infections and diabetes mellitus were excluded from the study.

2. Pregnant women were also excluded from the study.

\section{RESULTS}

Out of 100 patients, 71 were males and 29 were females. Microalbuminuria was observed in 23 patients. Presence of microalbuminuria in different age groups was presented in Table 1. Distribution of microalbuminuria according to sex was shown in Table 2. Distribution of microalbuminuria among different groups depending upon the duration of HTN was shown in Table 3. Microalbuminuria was present in $80 \%$ of patients with duration of hypertension more than 10 years.

\begin{tabular}{|c|c|c|c|}
\hline $\begin{array}{c}\text { Age } \\
\text { (In } \\
\text { years) }\end{array}$ & $\begin{array}{c}\text { Number of } \\
\text { Cases }\end{array}$ & Microalbuminuria & \% \\
\hline $30-39$ & 7 & 0 & 0.0 \\
\hline $40-49$ & 22 & 4 & 18.2 \\
\hline $50-59$ & 24 & 10 & 41.7 \\
\hline $60-69$ & 35 & 7 & 20.0 \\
\hline $70-79$ & 12 & 2 & 16.7 \\
\hline \multicolumn{3}{|c|}{ Table 1: Distribution of Microalbuminuria } \\
according to the Age Group \\
\hline
\end{tabular}

\begin{tabular}{|c|c|c|c|}
\hline Sex & $\begin{array}{c}\text { Number of } \\
\text { Cases }\end{array}$ & Microalbuminuria & $\%$ \\
\hline Male & 71 & 16 & 22.5 \\
\hline Female & 29 & 7 & 24.1 \\
\hline \multicolumn{3}{|c|}{ Table 2: Distribution of Microalbuminuria } \\
according to Sex
\end{tabular}

Out of 23 patients with microalbuminuria, 20 patients had 'Grade II' fundus changes. Out of 77 patents in the group 'Without Microalbuminuria,' 43 patients had normal fundus and 34 patients had 'Grade I' fundus changes $(\mathrm{p}<0.002)$. Lipid profile of the microalbuminuric patients was found to be normal in 5 patients and abnormal in 18 patients; $92 \%$ of the patients without microalbuminuria had normal lipid profile $(\mathrm{p}<0.001)$.

Among 100 hypertensive patients in our study, 24 had Left Ventricular Hypertrophy (LVH). Out of this group of 24 patients, microalbuminuria and LVH were present in 14 patients $(\mathrm{p}<0.001)$. Computerized Tomographic Scan (CT) was done in 30 patients; 26 patients showed abnormal CT findings, out of which 16 were with microalbuminuria $(\mathrm{p}<0.001)$. A high positive correlation $\left(X^{2}=56.324, \quad p<0.001\right)$ between microalbuminuria and target organ damage was observed.

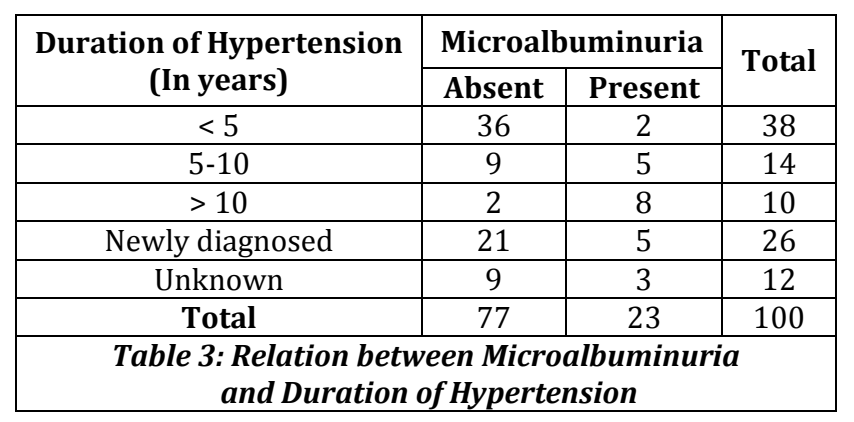

\section{DISCUSSION}

The prevalence of microalbuminuria in our study was $23 \%$. This finding was in accordance to the studies done by Hitha et al.(7) and Sharma et al.(8) Prevalence of microalbuminuria in our study was low when compared to the studies done by Sabharwal et al.(9) and Bibek et al.(10)

In the present study, there was no significant difference between prevalence of microalbuminuria in men and women. This finding was in accordance to the study done by Sabharwal et al.(9) and our finding was in contrary to the findings observed in the study done by Pontremoli et al.(11) where microalbuminuria was observed to be more in males.

In our study, microalbuminuria was found to have a positive correlation with the duration and severity of hypertension, which was similar to the finding in the studies done by Hitha et al.(7) Sharma et al.(8) Pontremoli et al.(11) and Cerasola et al.(12) In our study, microalbuminuria was found to be more prevalent in those patients with abnormal lipid profile. This finding was similar to the finding in the study done by Bianchi et al.(13)

In the present study, the prevalence of microalbuminuria was correlated positively with Cerebrovascular Accidents (CVA). This finding was similar to the findings observed in the studies done by Hitha et al.(7) Pontremoli et al.(11) and Kristian et al.(14) The present study showed a significant correlation between microalbuminuria and severity of retinopathy, which was similar to the observations in the studies done by Hitha et al.(7) and Cerasola et al.(12)

\section{CONCLUSION}

Prevalence of microalbuminuria increases with the age of the patient, the duration and severity of hypertension. Microalbuminuria had a statistically significant correlation with the target organ damage. Extensive screening for microalbuminuria is required in hypertensive subjects to assess the cardiovascular risk.

\section{REFERENCES}

1. Chobanian AV, Bakris GL, Black HR, Cushman WC, Green LA, Izzo JL, et al. The seventh report of the Joint National Committee on Prevention, Detection, Evaluation, and Treatment of High Blood Pressure: the JNC 7 Report. JAMA 2003;289:2560.

2. Slawson DC, Shaughnessy AF. Obtaining useful information from expert based sources. BMJ. 1997;314:947-9.

3. Burt VL, Whelton P, Roccella EJ, Brown C, Cutler JA, Higgins $\mathrm{M}$, et al. Prevalence of hypertension in the US adult population. Results from the Third National Health and Nutrition Examination Survey, 1988-1991. Hypertension 1995;25:305-13.

4. Bechung, Ooi Boon Seng, Chen BTM, Toh CCS and KHOO, Causes of hypertension in the young. Brit Med Jr, II, 744, 1970.

5. Aram VC, George LB, Henry RB, William CC, Lee AG, Joseph LI, et al. The Seventh Report of the Joint National Committee on Prevention, Detection, Evaluation \& Treatment of High Blood Pressure; JAMA: 2003;289:256071.

6. David JK, Jacob WU, Richard AH, David AW, Maged SB, Robert MM. Lack of relationship between hypertension associated symptoms and blood pressure in hypertensive emergency department patients. American journal of emergency Medicine: 2005;(23)2:106-10.

7. Hitha B, Pappachan JM, Balachandran, Pillai $H$ : Microalbuminuria in patients with essential hypertension and its relationship to target organ damage. An Indian experience. Saudi J Kidney Dis Transpl 2008;19(3):411-9.

Chi square 26.609, $\mathrm{p}<0.001$. 
8. Sharma VK, Dubey TN, Jain RK: A study of microalbuminuria in essential hypertension and its correlation with duration and severity of hypertension JAPI 2008;10-2.

9. Sabharwal RK, Parduman singh: Incidence of microalbuminuria in hypertensive patients. Indian Journal of Clinical Biochemistry, 2008/23(1)71-5.

10. Bibek P, Binod KY, Ashwini KN, Bharat J, Kanak BR. Prevalence and Association of Microalbuminuria in Essential Hypertensive Patients. $\mathrm{N}$ Am J Med Sci 2012;4(8):331-5.

11. Pontremolli R, Leoncini G, Ravera M, Parodi D, Tomolillo C. Microalbuminuria; Cardiovascular and Renal Risk in Primary Hypertension. Journal of American Society of Nephrology 2002;13S:169-72.
12. Cerasola G, Cottore S, D'Ignoto, Grasso L. Microalbuminuria points out early renal \& CVS damages in EH: Revista Latina De Cardiologia; 2002;13:3.

13. Bianchi S, Baldani GD, Bigazzi R, Nenci R. Microalbuminuria in Essential HT: Journal of Nephrology 1997;(4):216-8.

14. Kristian W, Vittorio P, Michael H; Jonathan NB, Tapio A, Eva G. Urine Albumin Creatinine Ratio and echo LV structure and function in hypertensive patients with microalbuminuria with echo evidence of LVH- The LIFE study. American Heart Journal 2002;143(2):319-26. 